\title{
DeVElopMent of AN AXIAL-Piston HydRAUlic MAChINE OF A DRIVE SYSTEM
}

\author{
STAZHKOV, S.
}

Abstract: Technical characteristics of positive-displacement hydraulic machines determine the prospects of increased application for known positive properties of positive-displacement hydraulic drive to improve machines of modern technologies performance characteristics. The positive-displacement hydraulic drive has wide and varied range of application in modern technology. Traditionally, hydraulic drive is applied where the fast response, rapidity, small dimensions, large transmitted power and automated control are required. The throttle control of high-power hydraulic drive is limited due to the low efficiency of a control process. In return, an application of positive-displacement hydraulic drive is being restrained with comparatively high value of a start and reverse inert zone and, as a consequence, comparatively low speed adjustment range. That is resulting from volumetric and mechanical high level losses comprised hydraulic machines.

The article is devoted to the searches of hydromechanical processes in axial piston hydraulic machines and practical recommendations for it perfecting.

Key words: swashplate axial-piston hydraulic machines, hydrostatic unloading, piston bloke, inert zone
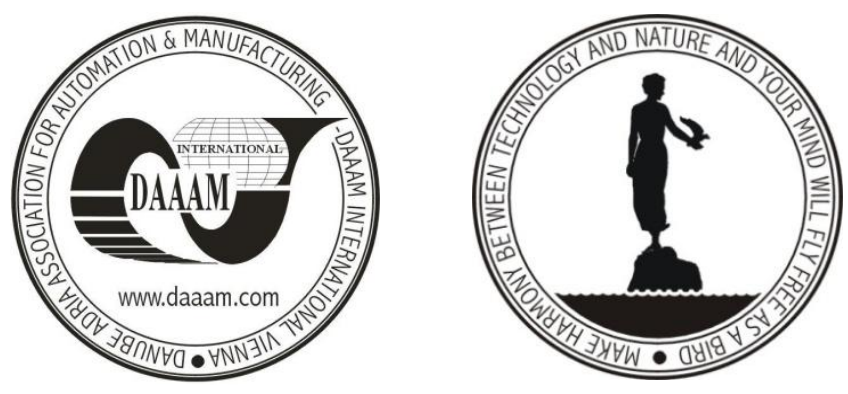

Authors' data: Stazhkov, S[ergey], Batic State Technical University named after Ustinov D. F. "VOENMEH", 1-st Krasnoarmeyskaya 13, 190005, Saint-Petersburg, Russia; Stazhkov@mail.ru

This Publication has to be referred as: Stazhkov, S[ergey] (2013) Development of an Axial-Piston Hydraulic Machine of a Drive System, Chapter 12 in DAAAM International Scientific Book 2013, pp. 277-296, B. Katalinic \& Z. Tekic (Eds.), Published by DAAAM International, ISBN 978-3-901509-94-0, ISSN 1726-9687, Vienna, Austria

DOI: $10.2507 /$ daaam.scibook.2013.12 
Stazhkov, S.: Development of an Axial-Piston Hydraulic Machine of a Drive System

\section{Introduction}

Global experience in the field of positive-displacement hydraulic drive allows assigning of two the most prevalent types of positive-displacement machines. These machines may be considered to be the base for engineering power-consuming drive with continuous loading conditions. These are:

- Bent axis hydraulic machines (BAH)

- Swashplate hydraulic machines (SWH)

The hydraulic machines with a bent axis (BAH) have comparatively low volumetric and mechanical level losses. As a consequence, reduced value of the start and reverse inert zone and increased adjustment range are occurred.

The hydraulic machines with swash plate (SWH) are more power-consuming, their dynamics and overall properties are higher.

Stated below research results and practical recommendations refer to the swashplate hydraulic machines. These machines are projected under a structural layout of widely known Sauer hydraulic machine type (see Fig.1)

These hydraulic machines father development may be concentrate on pressure forcing, as also expansion of regulation range. This is possible as a minimum level of steady rotation frequency may be reduced. Fundamentally, hybrid slider bearing has high alternative in design development.

An idea of researching involves theoretically and experimentally integrated approach. The subject is hydromechanical processes in main kinematic pair of SWH influenced with unsettled work kinematics of hydraulic machines running gears.

In addition it is necessary to determine and study interaction of main members of SWH variable structure mechanism, meeting surfaces of whose are divided with oil film; to define conditions that make type of friction changes; forecasting capabilities of volumetric and hydromechanical losses.

For these purposes have been done:

- $\quad$ Structural, kinematic and power analysis of SWH mechanism. The hydraulic drive was considered to be of variable structure as to define possible structure diagrams, requirements of its implementation and conversion.

- $\quad$ Analysis of SWH kinematic pairs operation in liquid friction in a wide range of temperature, velocity and pressure.

- $\quad$ Analysis of SWH piston blocks operation in boundary and mixed friction.

- Analysis of structural diagrams and construction of main members of SWH that are provide liquid friction and low volumetric losses during the zero and creep speeds.

- $\quad$ Analysis of pressure forced SWH 


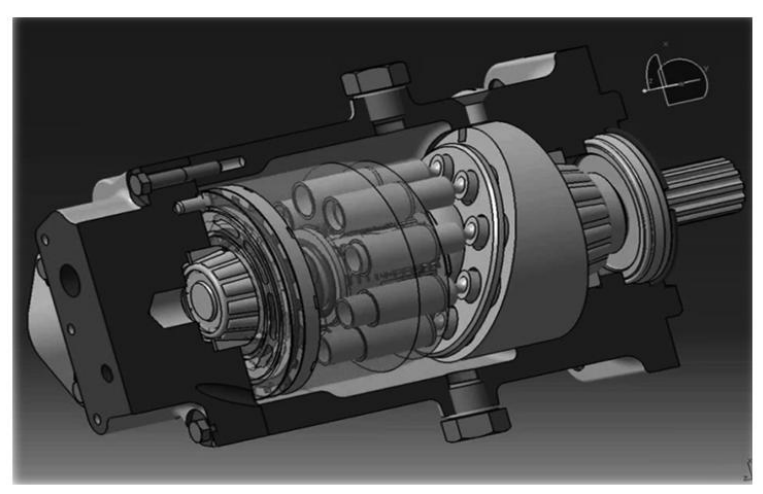

Fig. 1. Axial-piston hydraulic machine, Sauer type

\section{Power analysis}

For structural diagrams analysis and systematization of running gear spatial mechanism of the swashplate hydraulic machines for different mode and condition of its operation the main methods of mechanism and machines structural analysis were practiced.

Power analysis of piston mechanism was made basing on the method of superficial friction factor computation and others tribological characteristics.

For mathematical model design of hydromechanical processes in kinematic pairs of hydraulic machine running gears was used N. A. Selezkin's method. For numerical solution was used one of the most efficient numerical method for solution elliptic equation - the relaxation method.

Experimental researches were made with specially designed test-bench equipment and based on the inversion method of main observed members of hydraulic machines running gears.

As a result of SWH running gears mechanism studying (mechanism was considered to be of variable structure, depending on conditions and modes of drive application) the methodology of structural analysis, synthesis and structural classification of mechanism was engineered; different modes and conditions of drive application structural diagrams were investigated. Given methodology of structural analysis and synthesis is an evolution of Assur's method, was used for spatial mechanism analysis.

The next step of investigation was dedicated to analysis of microkinematics special feature of SWH variable structure mechanism. They depend on conditions and modes of application. The kinematic of main cycle of operation and the one for mechanism with redundant degree of freedom were studied. Cycle of operation is a cycle, by which mechanism operates as the first degree mechanism does (without involving a passive links). A special focus was on microkinematic investigation relatively shifting of meeting surfaces of hydraulic machines running gears within the gap filled with a working fluid. Based on analysis of a macro- and microkinematic of meeting surfaces relatively shifting, the mathematical relations of every kinematic 
pair of SWH running gear were derived. These are a foundation for creating a mathematical model of hydromechanical processes in gaps for liquid friction.

Based on power analysis (see Fig. 2) the relations for friction force computation in piston pairs were derived for hydraulic machines operated in pumping mode in wide variety conditions of applications, including the extreme one.

$$
T^{p}=\frac{F_{p}}{\left(\frac{1}{f_{s p}^{p} \cdot \operatorname{tg} \gamma}-1\right)}
$$

where $f_{s p}^{p}$ are superficial friction factors in motor and pumping mode respectively;

$$
f_{s u}^{p},=\frac{\left(2 \bar{\ell}_{c a}+\bar{\ell}_{a b}\right) \cdot f+f^{2}}{\bar{\ell}_{a b}-2 \bar{r}_{c} \cdot f}
$$

$f$ - friction coefficient in piston - cylinder unit (PCU), $l_{c a}$ - piston extension ( distance between center of piston spherical joint and fairlead bush external surface) $l_{a b}$ - length of fairlead bush $r_{C}$ - the center of a piston spherical joint shift relative to piston longitudinal axis $\gamma$ - the swash plate displacement angle $F_{P}$ - axial force operated upon a piston $d_{\mathrm{n}}$ - piston diameter

Derived relations between tangential and axial component of friction PCU depending on SWH mode of application, results of experimental research and energy characteristics of PCU - the main source of mechanical losses - were a basis for father calculations. That is allowed to determine bounds for variation of design factors range of SWH running gears mechanism whereby a locking of kinematic pair is ruled out.

By using the methods of theoretical hydromechanics was found a solution for problem of hybrid loading capacity for bearing surfaces of running gear mechanism members of hydraulic machines.

The mathematical models of hydromechanical processes in arbitrary shaped gaps that divide the surfaces of kinematic pairs are given below. They were derived by using the base of research results of meeting surfaces relatively shifting of running gear members of hydraulic machines (see Fig. 3, 4). 


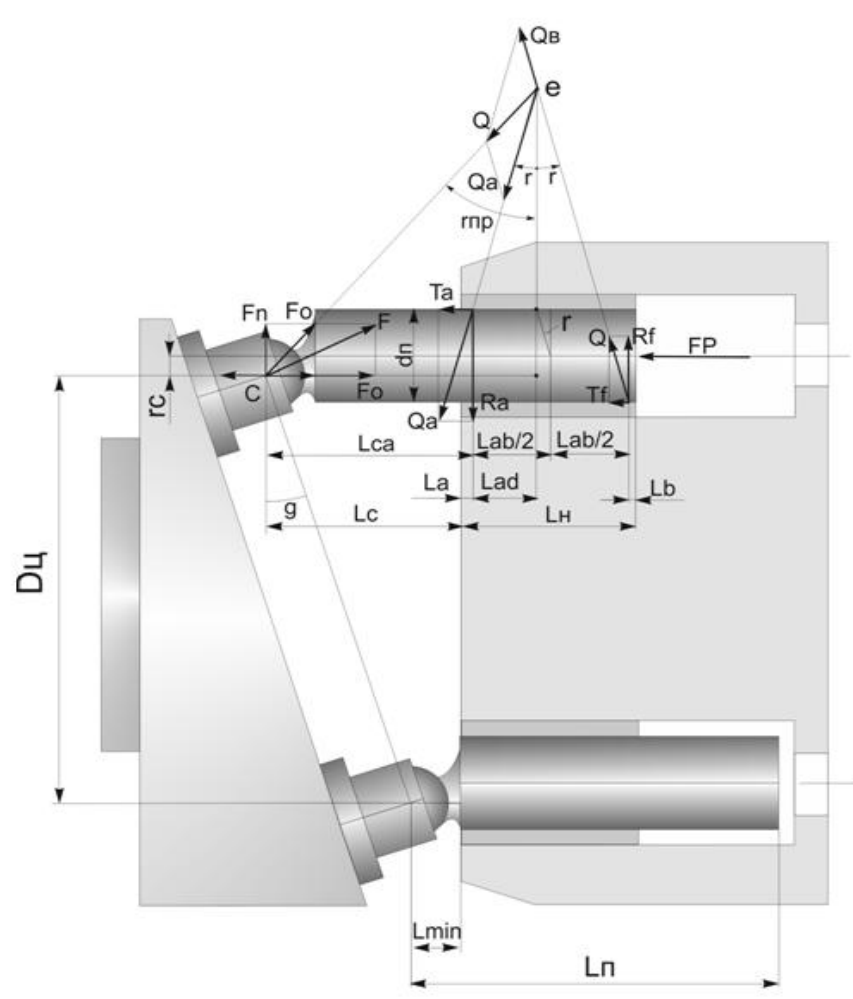

Fig. 2. Forces profile in pumping mode

\subsection{Piston - Cylinder Unit}

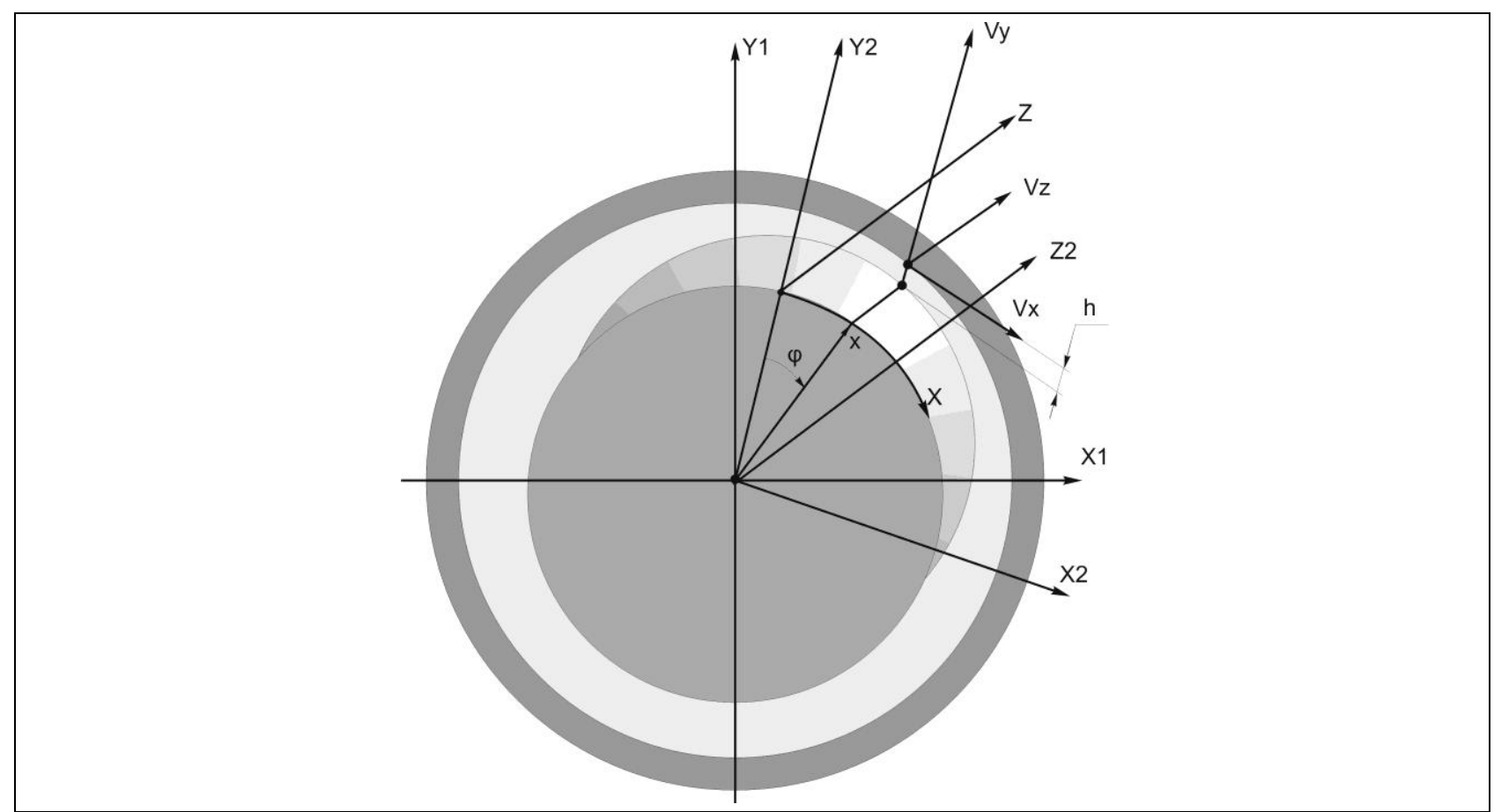

Fig. 3. Piston - cylinder unit 


$$
\begin{gathered}
\frac{1}{r_{n}^{2}} \cdot\left[\frac{\partial}{\partial \varphi}\left(h^{3}(\varphi, z) \frac{\partial p}{\partial \varphi}\right)+\frac{\partial}{\partial z}\left(h^{3}(\varphi, z) \frac{\partial p}{\partial z}\right)\right]= \\
=-\frac{6 \mu}{r_{n}} \cdot\left(\frac{\partial h(\varphi, z)}{\partial \varphi}\right) \cdot V_{\varphi}-6 \mu \cdot\left(\frac{\partial h(\varphi, z)}{\partial z}\right) \cdot V_{z}+12 \mu \cdot V_{r},
\end{gathered}
$$

where:

$$
\begin{gathered}
V_{r}=\left(V_{\theta}\right)_{r}=\left(\frac{\partial \theta}{\partial t}\right) \cdot z \cdot \cos \left(\alpha_{n}-\varphi\right), \\
V_{\varphi}=\left(V_{\theta}\right)_{\varphi}+\left(V_{\alpha_{n}}\right)_{\varphi}+\left(V_{\psi}\right)_{\varphi}=\left(\frac{\partial \theta}{\partial t}\right) \cdot z \cdot \sin \left(\alpha_{n}-\varphi\right)+r_{n} \cdot\left(\frac{d \alpha_{n}}{d t}+\frac{d \psi}{d t}\right), \\
V_{z \backslash}=\left(V_{\theta}\right)_{z}+\left(V_{B-n}\right)_{z}=-\left(\frac{\partial \theta}{\partial t}\right) \cdot r_{n} \cdot \cos \left(\alpha_{n}-\varphi\right)+0,5 D_{u} \cdot \omega \cdot \operatorname{tg}(\gamma) \cdot \sin (\alpha), \\
h(\varphi, z)=h_{0}+z \cdot \sin (\theta) \cdot \cos (\varphi),
\end{gathered}
$$

$\theta$ - angle between piston and cylinder axes (nutation angle),

$\psi$ - angle between axis, that is perpendicular to a piston tilt plane and axis, that is perpendicular to piston rotation axis (precession angle),

$\alpha_{n}$ - piston proper rotation angle (roll angle),

$h(\varphi, z), h_{0}$ - value of the gap between piston support surfaces and fairlead bush that are of eccentric or concentric arrange correspondingly,

$z, \varphi$ - piston support surfaces coordinates for arbitrary point,

$D_{\text {ч }}$ - diameter of circle which cylinder axes arrange.

\subsection{Piston Shoe - Shoe Plate}

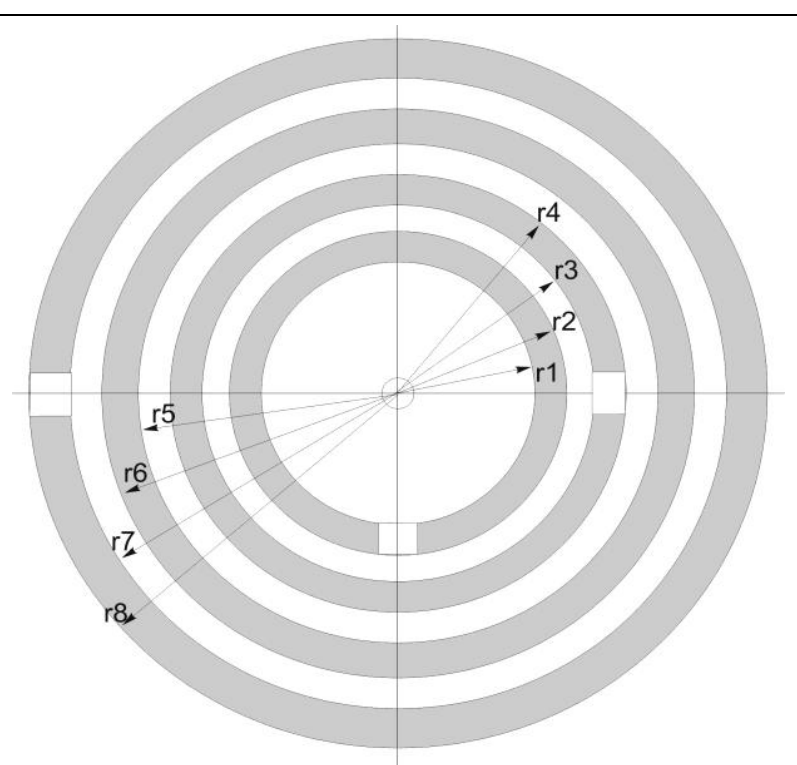

Fig. 4. Mounting surface of hydrostatic shoe 


$$
\begin{gathered}
\frac{1}{r} \cdot \frac{\partial}{\partial r}\left(h^{3}(\varphi, z) r \cdot \frac{\partial p}{\partial r}\right)+\frac{1}{r} \cdot \frac{\partial}{\partial \varphi}\left(h^{3}(\varphi, z) r \cdot \frac{\partial p}{\partial \varphi}\right)= \\
=-6 \mu \cdot\left(\frac{\partial h(\varphi, r)}{\partial r}\right) \cdot\left(V_{\theta}\right)_{\varphi}-\frac{6 \mu}{r} \cdot\left[\frac{\partial h(\varphi, \mathrm{r})}{\partial \varphi}\right] \cdot\left[\left(V_{\psi}\right)_{\varphi}+\left(V_{\theta}\right)_{\varphi}+\left(V_{\alpha}\right)_{\varphi}\right]+12 \mu \cdot\left[\left(V_{\theta}\right)_{z}+\left(V_{z}\right)_{z}\right],
\end{gathered}
$$

where:

$$
\begin{gathered}
\left(V_{\theta}\right)_{\varphi}=\left(\frac{\partial \theta}{\partial t}\right) \cdot H \cdot \sin (\varphi-\alpha), \\
\left(V_{\theta}\right)_{r}=\left(\frac{\partial \theta}{\partial t}\right) \cdot H \cdot \cos (\varphi-\alpha), \\
\left(V_{\theta}\right)_{z}=\left(\frac{\partial \theta}{\partial t}\right) \cdot r \cdot \sin (\varphi-\alpha), \\
\left(V_{\alpha}\right)_{\varphi}=-\left(\frac{\partial \alpha}{\partial t}\right) \cdot r, \\
\left(V_{\psi}\right)_{\varphi}=-\left(\frac{\partial \psi}{\partial t}\right) \cdot r, \\
h(\varphi, r)=h_{0}+r \cdot \sin (\psi) \cdot \sin (\varphi-\alpha),
\end{gathered}
$$

$\theta, \psi, \alpha$ - Euler coordinates that determine the piston shoe or valve plate position in regard to meeting mounting surfaces of swash plate and cylinder block correspondingly,

$h(\varphi, r), h_{0}$ - value of the gap between meeting surfaces of given kinematic pairs when the surfaces are no equidistant or equidistant correspondingly, $r, \varphi$ - mounting surfaces coordinates for arbitrary point of piston shoe or valve plate, $H$ - for kinematic pair "valve plate - cylinder block" - the distance the center of spline joint of cylinder block and hydraulic machine driving shift from mounting surfaces of valve plate; for kinematic pair "piston shoe - shoe plate" - the distance the center of spherical joint from mounting surfaces of piston shoe.

The same relation may be applied for kinematic pair valve plate - cylinder block.

Next, the certain results of calculation experience are listed. The computations were based one of the most efficient numerical method for solution elliptic equation the relaxation method. The results are the pressure profiles in kinematic pairs gaps of SWH running gears. The profiles depend on characteristics that identify a shape of gap, speed of relative movement of meeting surfaces of links and also viscosity of hydraulic fluid.

In figure 5 the pressure profile in gap of CPU with piston diameter is shown.

The nature of this profile, which was derived by means of calculation, perfectly well corresponds with H. Regenbogen's one (Regenbogen, 1978), which was a result 
of experience with the same characteristics of gaps, speeds and temperatures. A disarrangement of maximum value for pressure in both relations is no more then $10 \%$.

As a result, were derived the relations for load bearing and power (loss of power, coefficient of performance) characteristics for kinematic pairs of hydraulic machines running gears in undegraded operation.

The mechanical loss evaluation allow to assert that in this case the kinematic pairs of hydraulic machines running gears mechanisms are mostly operated in liquid friction.

Mentioned characteristics that were derived by integrating the fields of pressure in gaps of kinematic pairs make possible to elaborate recommendation at the design stage for choosing the size and design for main mounting surfaces of mechanism running gears members. That allows expanding the range of application modes of hydraulic machines wherein the kinematic pairs are in liquid friction.

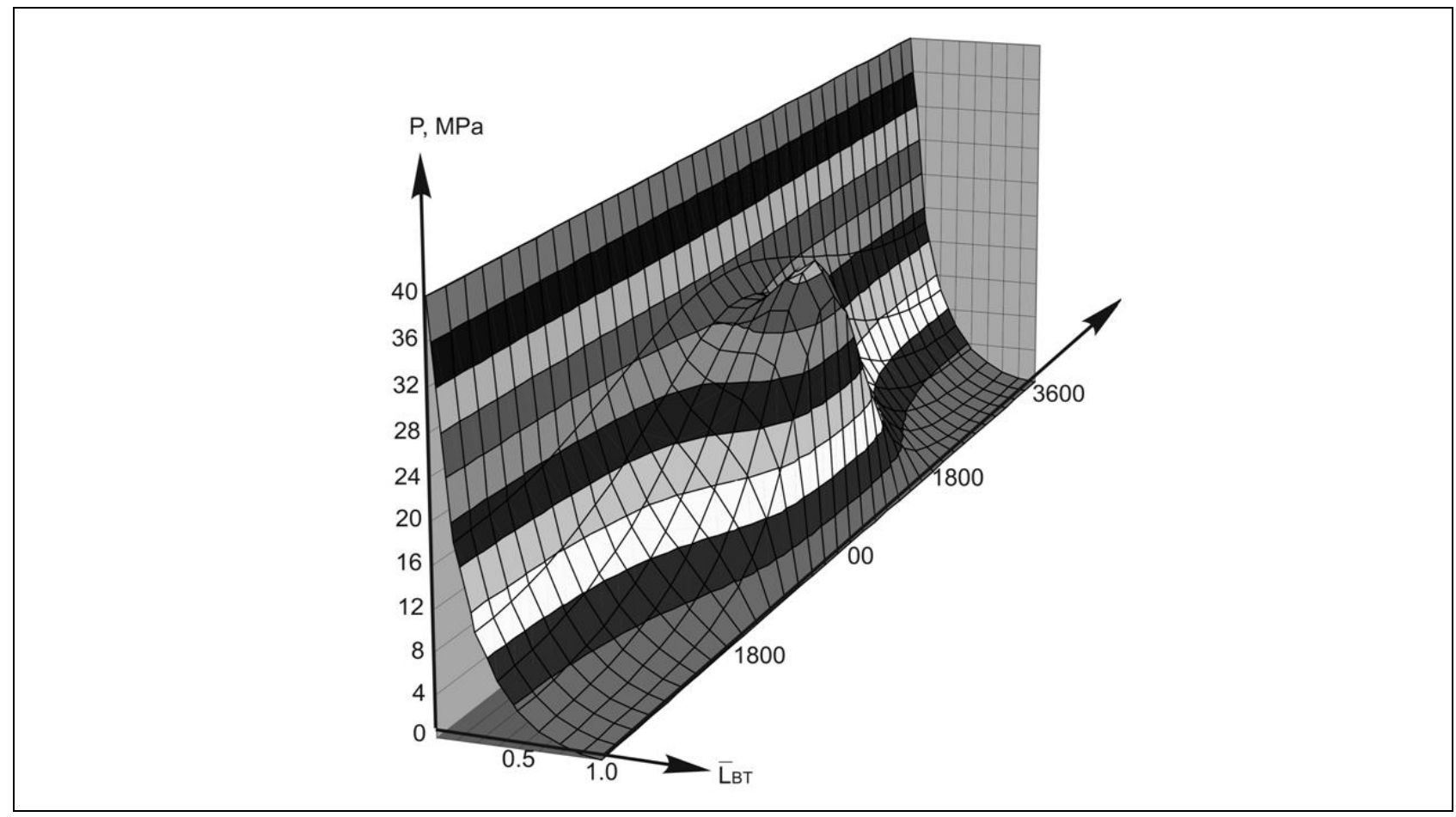

Fig. 5. The pressure profile in gap of CPU with piston diameter $d_{p}=31,5 \cdot 10^{-3} \mathrm{~m}$

\section{The Index of Friction}

One of the most important characteristic that enable to estimate a level of mechanical loss is an index of friction. As it known the index is the ratio between forces of friction and normal component of external forces.

For liquid friction, when the metal-to-metal contact of mating surfaces is missing, the value of oil firm response (loading capacity of oil firm) numerically equal to normal component of external forces. This may be used for computation of the coefficient of liquid friction that in this case (considering another physical nature 
of mentioned force) would be more correctly to designate as, for instance, a specific friction force.

The following references allow calculating the specific friction force by using the pressure profile in of CPU:

$$
f_{f r}^{p}=\frac{L_{b} \cdot \sqrt{\left(T_{a x}^{p}\right)^{2}+\left(T_{\tau}^{p}\right)^{2}}}{M^{p}},
$$

where:

$T_{a x}^{p}=\int_{0}^{2 \pi} \int_{z 1}^{z 2} \tau_{z} r d \varphi d z-$ axial component of friction force in CPU,

$T_{\tau}^{p}=\int_{0}^{2 \pi} \int_{z 1}^{z 2} \tau_{\varphi} r d \varphi d z$ - tangential component of friction force in CPU,

$M^{p}=\sqrt{\left(M_{x}^{p}\right)^{2}+\left(M_{y}^{p}\right)^{2}}$ - sum of torque in gap for pressure profile counter to piston tilt relatively to the bush of cylinder,

$$
\begin{aligned}
& M_{x}^{p}=\int_{0}^{2 \pi} \int_{z 1}^{z 2} p(z, \varphi) \cdot \cos (\varphi) \cdot r \cdot z d \varphi \Delta z, \\
& M_{y}^{p}=\int_{0}^{2 \pi} \int_{z 1}^{z 2} p(z, \varphi) \cdot \sin (\varphi) \cdot r \cdot z d \varphi \Delta z,
\end{aligned}
$$

$L_{b}$ - length of fairlead bush,

$z_{1}, z_{2}, \Delta z$ - axial coordinates of edges for fairlead bush and coordinate that determine arbitrarily chosen piston cross-section.

Another important characteristic to estimate the power losses is hydraulic fluid consumption through the gaps in kinematic pairs.

Following relation is the hydraulic fluid consumption for PCU:

$$
Q=-\left(\frac{r_{n}}{12 \mu}\right) \cdot \int_{0}^{2 \pi} h^{3} \cdot\left(\frac{d p}{d z}\right) d \varphi+0,5 \cdot r_{n} \cdot \int_{0}^{2 \pi} h \cdot V d \varphi
$$

The same relations were derived for another kinematic pairs of SWH running gears mechanism for calculations of specific friction force and consumption. These relations were used for computations of hydraulic machine loss of power and coefficient of performance for pumping and motor mode.

The base for integral parameters of kinematic pairs computation was an array variable. In tables 1, 2, 3 listed variables that show design factors, kinematic of 
Stazhkov, S.: Development of an Axial-Piston Hydraulic Machine of a Drive System

running gear mechanism of hydraulic machine, pressure and viscosity of hydraulic fluid.

\begin{tabular}{|c|c|c|c|c|c|c|c|}
\hline $\begin{array}{c}\text { Paramete } \\
\mathrm{r}\end{array}$ & $\begin{array}{c}\text { Identifi } \\
\text { er }\end{array}$ & $\begin{array}{c}\text { Reference } \\
\text { variable }\end{array}$ & \multicolumn{5}{|c|}{ Array variable } \\
\hline$h_{0}^{p}, \mathrm{~m}$ & $\mathrm{~h} 0$ & $16 \cdot 10^{-6}$ & $10 \cdot 10^{-6}$ & $13 \cdot 10^{-6}$ & $16 \cdot 10^{-6}$ & $19 \cdot 10^{-6}$ & $22 \cdot 10^{-6}$ \\
\hline$\gamma, \mathrm{rad}$ & $\mathrm{ga}$ & 0,314 & 0,01 & 0,078 & 0,157 & 0,235 & 0,314 \\
\hline$\theta^{p}, \mathrm{rad}$ & $\mathrm{te}$ & $-3 \cdot 10^{-4}$ & 0 & $1,5 \cdot 10^{-4}$ & $3 \cdot 10^{-4}$ & $4,5 \cdot 10^{-4}$ & $6 \cdot 10^{-4}$ \\
\hline$\omega_{\alpha}^{p}, \mathrm{rad} / \mathrm{c}$ & $\mathrm{wap}$ & 0 & 0 & 75 & 150 & 225 & 300 \\
\hline$\omega_{\theta}^{p}, \mathrm{rad} / \mathrm{c}$ & $\mathrm{wt}$ & 0 & 0 & 0,1 & 0,2 & 0,3 & 0,4 \\
\hline$\omega_{\psi}^{p}, \mathrm{rad} / \mathrm{c}$ & $\mathrm{wp}$ & 0 & 0 & 75 & 150 & 225 & 300 \\
\hline$\omega, \mathrm{rad} / \mathrm{c}$ & $\mathrm{wa}$ & $270(0)$ & 1 & 75 & 150 & 225 & 299 \\
\hline$\mu^{p}, \mathrm{~Pa} \cdot \mathrm{c}$ & $\mathrm{mu}$ & $7 \cdot 10^{-3}$ & $2 \cdot 10^{-3}$ & $4 \cdot 10^{-3}$ & $6 \cdot 10^{-3}$ & $8 \cdot 10^{-3}$ & $10 \cdot 10^{-3}$ \\
\hline$L_{b}, \mathrm{~m}$ & $\mathrm{Lvt}$ & $33 \cdot 10^{-3}$ & $25 \cdot 10^{-3}$ & $30 \cdot 10^{-3}$ & $35 \cdot 10^{-3}$ & $40 \cdot 10^{-3}$ & $45 \cdot 10^{-3}$ \\
\hline$p_{0}, \mathrm{~Pa}$ & po & $10^{7}$ & $10^{6}$ & $13 \cdot 10^{6}$ & $26 \cdot 10^{6}$ & $38 \cdot 10^{6}$ & $50 \cdot 10^{6}$ \\
\hline
\end{tabular}

Tab. 1. Variables for kinematic pair "piston - cylinder"

\begin{tabular}{|c|c|c|c|c|c|c|c|}
\hline Parameter & $\begin{array}{c}\text { Identifi } \\
\text { er }\end{array}$ & $\begin{array}{c}\text { Reference } \\
\text { variable }\end{array}$ & \multicolumn{5}{|c|}{ Array variable } \\
\hline$h_{0}^{v}, m$ & h0 & $10 \cdot 10^{-6}$ & $6 \cdot 10^{-6}$ & $10 \cdot 10^{-6}$ & $14 \cdot 10^{-6}$ & $18 \cdot 10^{-6}$ & $22 \cdot 10^{-6}$ \\
\hline$\psi^{v}, \mathrm{rad}$ & $\mathrm{ps}$ & 0 & 0 & 1,57 & 3,14 & 4,71 & 6,28 \\
\hline$\theta^{v}, \mathrm{rad}$ & $\mathrm{te}$ & 0 & 0 & $3 \cdot 10^{-5}$ & $6 \cdot 10^{-5}$ & $9 \cdot 10^{-5}$ & $12 \cdot 10^{-5}$ \\
\hline$\omega_{\alpha}^{v}, \mathrm{rad} / \mathrm{c}$ & $\mathrm{wa}$ & 270 & 0 & 75 & 150 & 225 & 299 \\
\hline$\omega_{\theta}^{v}, \mathrm{rad} / \mathrm{c}$ & $\mathrm{wt}$ & 0 & 0 & 0,05 & 0,1 & 0,15 & 0,2 \\
\hline$\omega_{\psi}^{v}, \mathrm{rad} / \mathrm{c}$ & $\mathrm{wp}$ & 0 & 0 & 75 & 150 & 225 & 300 \\
\hline$V_{z}^{v}, \mathrm{~m} / \mathrm{c}$ & $\mathrm{v} 6$ & $10^{-5}$ & 0 & $0,5 \cdot 10^{-5}$ & $10^{-5}$ & $1,5 \cdot 10^{-5}$ & $2 \cdot 10^{-5}$ \\
\hline$\mu^{v}, \mathrm{~Pa} \cdot \mathrm{c}$ & $\mathrm{mu}$ & $7 \cdot 10^{-3}$ & $2 \cdot 10^{-3}$ & $4 \cdot 10^{-3}$ & $6 \cdot 10^{-3}$ & $8 \cdot 10^{-3}$ & $10 \cdot 10^{-3}$ \\
\hline
\end{tabular}

Tab. 2. Variable for kinematic pair "valve plane - cylinder block"

As reference variable were used the design factors of SWH members of running gears mechanisms of $89 \mathrm{~cm}^{3} / \mathrm{rev}$ displacement, also parameters by which the studied kinematic pairs operated in liquid friction. The ranges of variable parameters were determined according the modes of application of hydraulic machine. 
As a result were derived more than 600 charts of integral parameters. Some of them are shown in figures 7,8 .

The contrastive analysis of integral parameters allowed to estimate the rate of capacity loss in every kinematic pair of SWH running gear mechanism. That was a base for computation and determination the recommendation for development of members design factors for running gears.

As was stated above, the generalized criterions that specify the friction mode change is friction coefficient. Its computation for mixed and boundary friction should be based on experimental results.

\begin{tabular}{|c|c|c|c|c|c|c|c|}
\hline Parameter & Identifier & $\begin{array}{c}\text { Reference } \\
\text { variable }\end{array}$ & \multicolumn{5}{|c|}{ Array variable } \\
\hline$h_{s p 0}, m$ & $\mathrm{~h} 0$ & $22 \cdot 10^{-6}$ & $14 \cdot 10^{-6}$ & $17 \cdot 10^{-6}$ & $20 \cdot 10^{-6}$ & $23 \cdot 10^{-6}$ & $26 \cdot 10^{-6}$ \\
\hline$\psi^{s p}, \mathrm{rad}$ & $\mathrm{ps}$ & $7 \cdot 10^{-4}$ & 0 & $3 \cdot 10^{-4}$ & $6 \cdot 10^{-4}$ & $9 \cdot 10^{-4}$ & $12 \cdot 10^{-4}$ \\
\hline$\theta_{s p}, \mathrm{rad}$ & $\mathrm{te}$ & 3,927 & 0 & 1,57 & 3,14 & 4,71 & 6,28 \\
\hline$\omega_{s p p}, \mathrm{rad} / \mathrm{c}$ & $\mathrm{wa}$ & $270(0)$ & 1 & 75 & 150 & 225 & 299 \\
\hline$\omega_{s p \theta}, \mathrm{rad} / \mathrm{c}$ & $\mathrm{wt}$ & $270(0)$ & 0 & 75 & 150 & 225 & 300 \\
\hline$\omega_{s p \psi}, \mathrm{rad} / \mathrm{c}$ & $\mathrm{wp}$ & $18 \cdot 10^{-2}(0)$ & 0 & $8 \cdot 10^{-2}$ & $15 \cdot 10^{-2}$ & $23 \cdot 10^{-2}$ & $30 \cdot 10^{-2}$ \\
\hline$V_{s p z}, \mathrm{rad} / \mathrm{c}$ & $\mathrm{v} 6$ & $-24 \cdot 10^{-4}(0)$ & $-38 \cdot 10^{-4}$ & $-31 \cdot 10^{-4}$ & $-24 \cdot 10^{-4}$ & $-17 \cdot 10^{-4}$ & $-10 \cdot 10^{-4}$ \\
\hline$\mu_{s p}, \mathrm{~Pa} \cdot \mathrm{c}$ & $\mathrm{mu}$ & $7 \cdot 10^{-3}$ & $2 \cdot 10^{-3}$ & $4 \cdot 10^{-3}$ & $6 \cdot 10^{-3}$ & $8 \cdot 10^{-3}$ & $10 \cdot 10^{-3}$ \\
\hline$r_{s p}, \mathrm{~m}$ & $\mathrm{r} 1$ & $9,285 \cdot 10^{-3}$ & $8,5 \cdot 10^{-3}$ & $8,8 \cdot 10^{-3}$ & $9 \cdot 10^{-3}$ & $9,3 \cdot 10^{-3}$ & $9,5 \cdot 10^{-3}$ \\
\hline
\end{tabular}

Tab. 3. Variable for kinematic pair "piston shoe - shoe plate"

H. Regenbogen's and K. T. Renyus' works present that computations of a friction coefficient in kinematic pairs were made with simplified method. The friction coefficient is the ration of friction forces to the axial force exerted on the piston. For SWH with swash plate tilt $\gamma=18^{\circ}$ numerically equal to the sum of normal load. In spite of the conventionality (contradictory definition of friction coefficient), given methodology allow to make a computation of friction coefficient in liquid friction with the specified degree of accuracy. However, for mixed and especially boundary friction mentioned computation method don't applied. First of all, because of the existence of a cross effects of axial force exerted on the piston and friction force in PCU. 


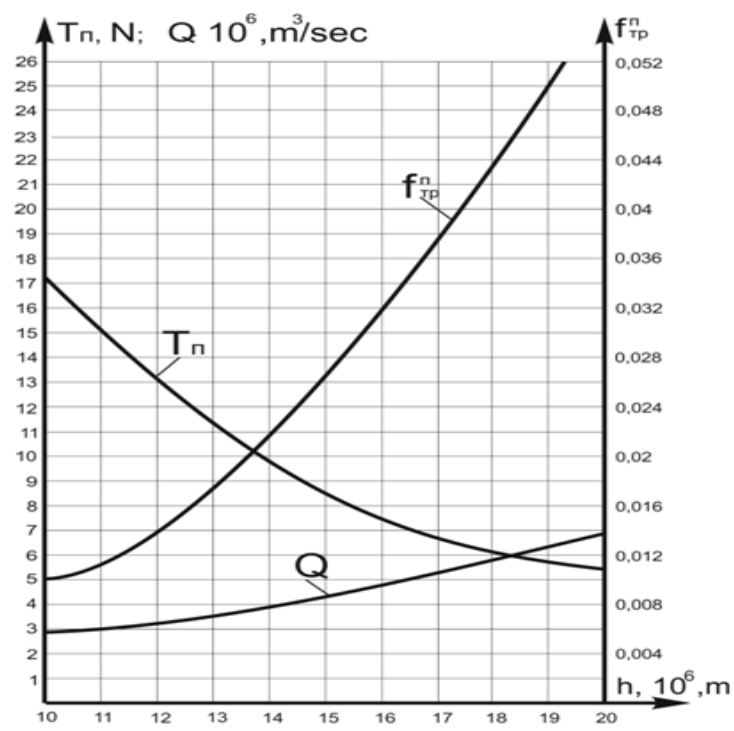

Fig. 6. Curves of displacement, axial friction force, specific friction force versus the value of the gap in CPU

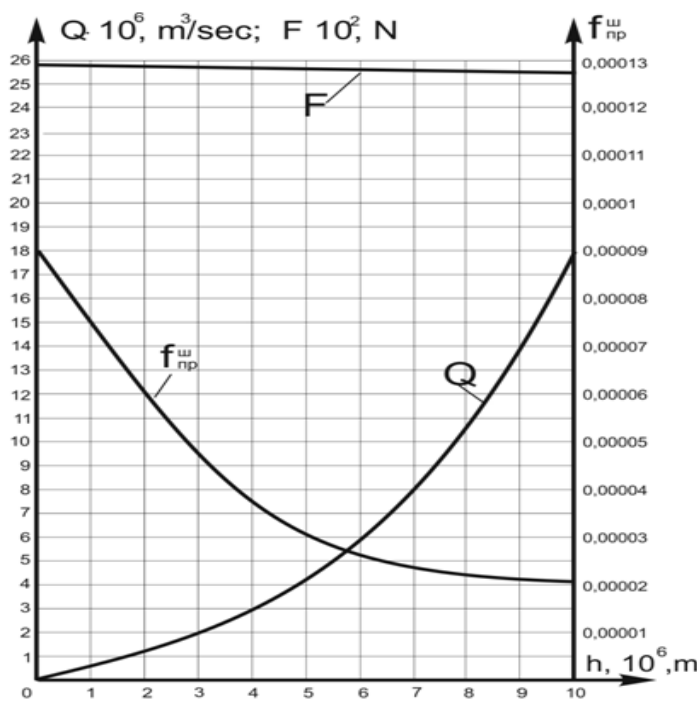

Fig. 7. Curves of displacement, external force, specific friction of fluid versus the value of gap in "piston - mounting shoe" kinematic pair

On the base of power analysis was developed a method that by using the experimental results of axial component of friction force in PCU allow to calculate a tribological characteristics of PCU with high degree of accuracy. Besides that the friction coefficient in wide range of hydraulic machine application, including the start up and forcing modes by power and limited speed may be calculated by this method.

$$
f=\frac{-k_{1} \cdot F_{p}}{T}+\sqrt{\left(\frac{k_{1} \cdot F_{p}}{T}\right)^{2}+k_{2}},
$$

where: 


$$
T=T_{p}+T_{m},
$$

$T_{p}=\left(\frac{L_{a b}+2 \cdot r_{c} \cdot f}{\left(2 L_{c a}+L_{a b}\right) \cdot f \cdot \operatorname{tg}(\gamma)}-1\right)^{-1}-$ axial component of friction force in pumping mode,

$T_{m}=\left(\frac{L_{a b}-2 \cdot r_{c} \cdot f}{\left(2 L_{c a}+L_{a b}\right) \cdot f \cdot \operatorname{tg}(\gamma)}+1\right)^{-1}-$ axial component of friction force in motor mode,

$$
k_{1}=\left(\frac{2 L_{c a}}{L_{a b}}+1\right) \cdot \operatorname{tg}(\gamma) \cdot k_{2},
$$

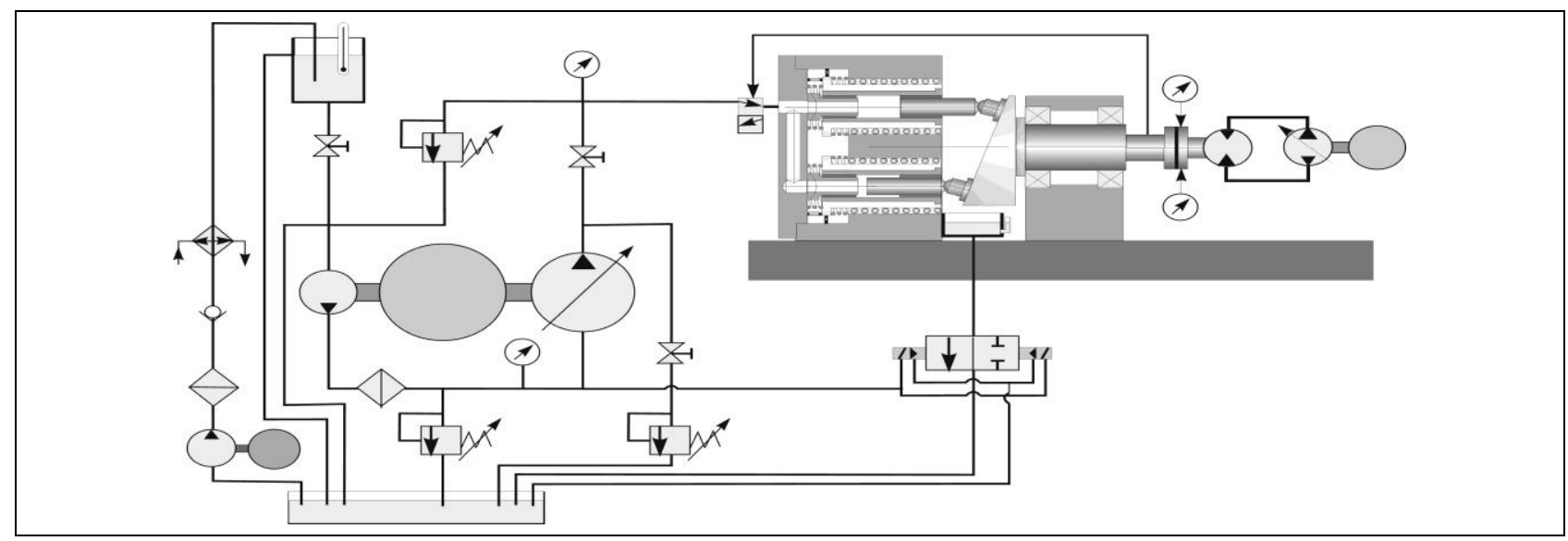

Fig. 8. Experimental plan

$$
k_{2}=\left(\frac{L_{a b}}{2 r_{c}-\left(2 L_{c a}+\operatorname{Lab}\right) \cdot \operatorname{tg}(\gamma)}\right)^{2},
$$

$F_{p}=\pi \cdot r_{n}^{2} \cdot p-$ axial force exerted on the piston.

\section{The Experiment}

For value determination of the friction forces in hydraulic machines CPU, was developed a two - cylinder experimental plant, the scheme of that is shown in fig. 8 .

This plant may also be used for researching of volumetric loss and relative motion speeds of piston mechanisms members for basic and developed hydraulic machines in wide range of application (angular frequency $0 \ldots 350 \mathrm{rad} / \mathrm{second}$, operated pressure $0 \ldots 50 \mathrm{MPa}$ ).

In figures 13, 14 are shown typical cycle schemes of friction force and relative motion speeds of piston mechanisms members at creep speeds and driving shift angular frequency changing from 10 to $300 \mathrm{rad} / \mathrm{second}$. 


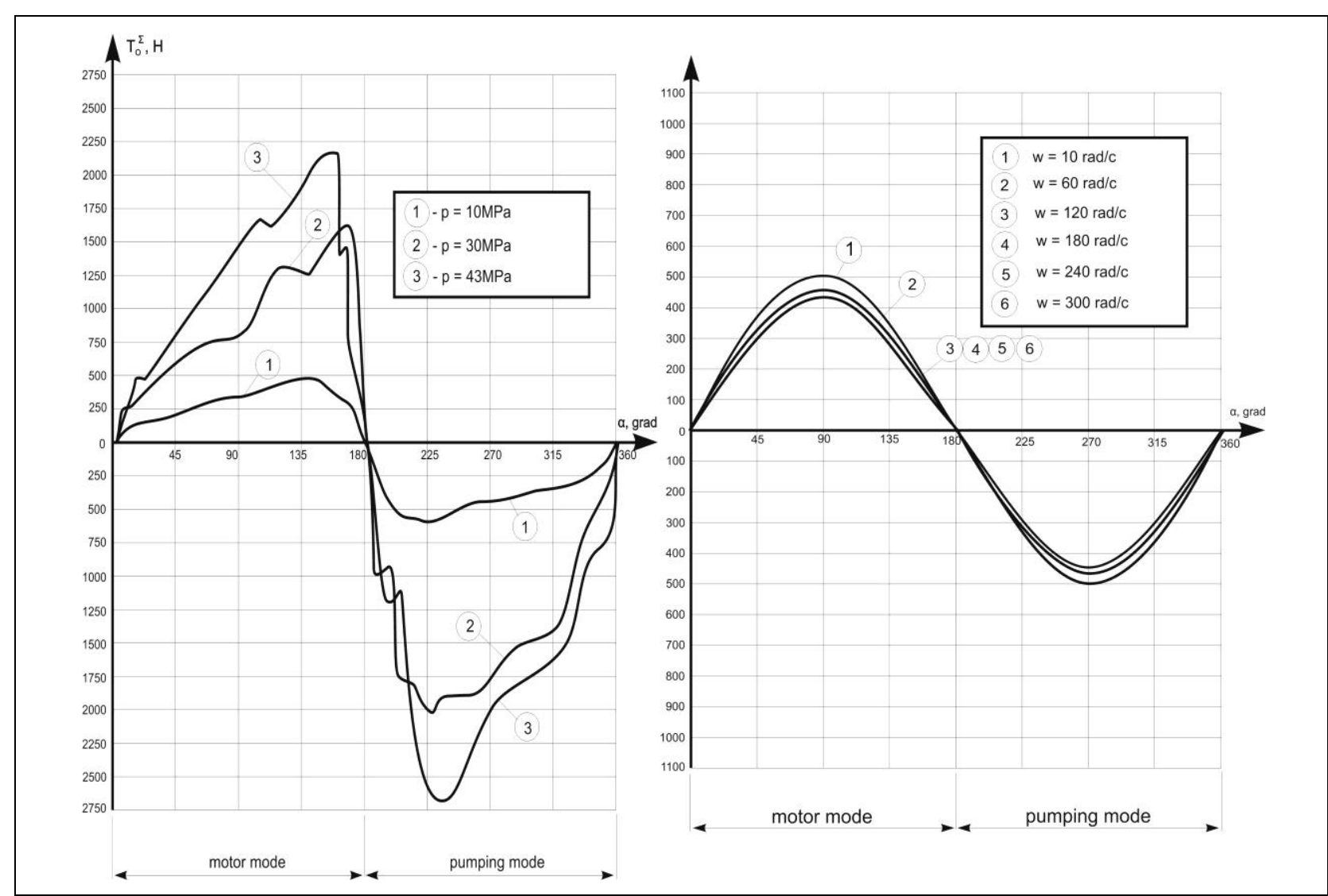

Fig. 9. Cycle schemes of axial friction Fig. 10. Cycle schemes of axial force component in CPU with relative gap $0,121 \%$ in breakaway mode and creep speeds (up to $0,1 \mathrm{rad} / \mathrm{second}$ ) friction force component in CPU with angular frequency $0 \ldots 350 \mathrm{rad} / \mathrm{second}$, operated pressure $0 \ldots 50 \mathrm{MPa}$ with the temperature

Following characteristic curves of tribological characteristics and fluid leaks through the kinematic pairs gaps were derived by the automated data processing of experimental researches. Some of them are shown in the figures 11, 12.

On the base of descried above researches was made a practical recommendation for running gear members of SWH mechanism development.

For hydraulic machines as part of forceful drive that operated under the high pressure and speed for a long time, the most important characteristic is coefficient of performance. Its value is determined by mechanical and volumetric losses in kinematic pairs of running gear.

For high-accuracy drives the most important characteristics are fast response and rapidity. For hydraulic machines, operated under the extreme conditions, substantially impose the requirements for fault-free performance in short-term overloads, start up and other critical operation and work conditions. 

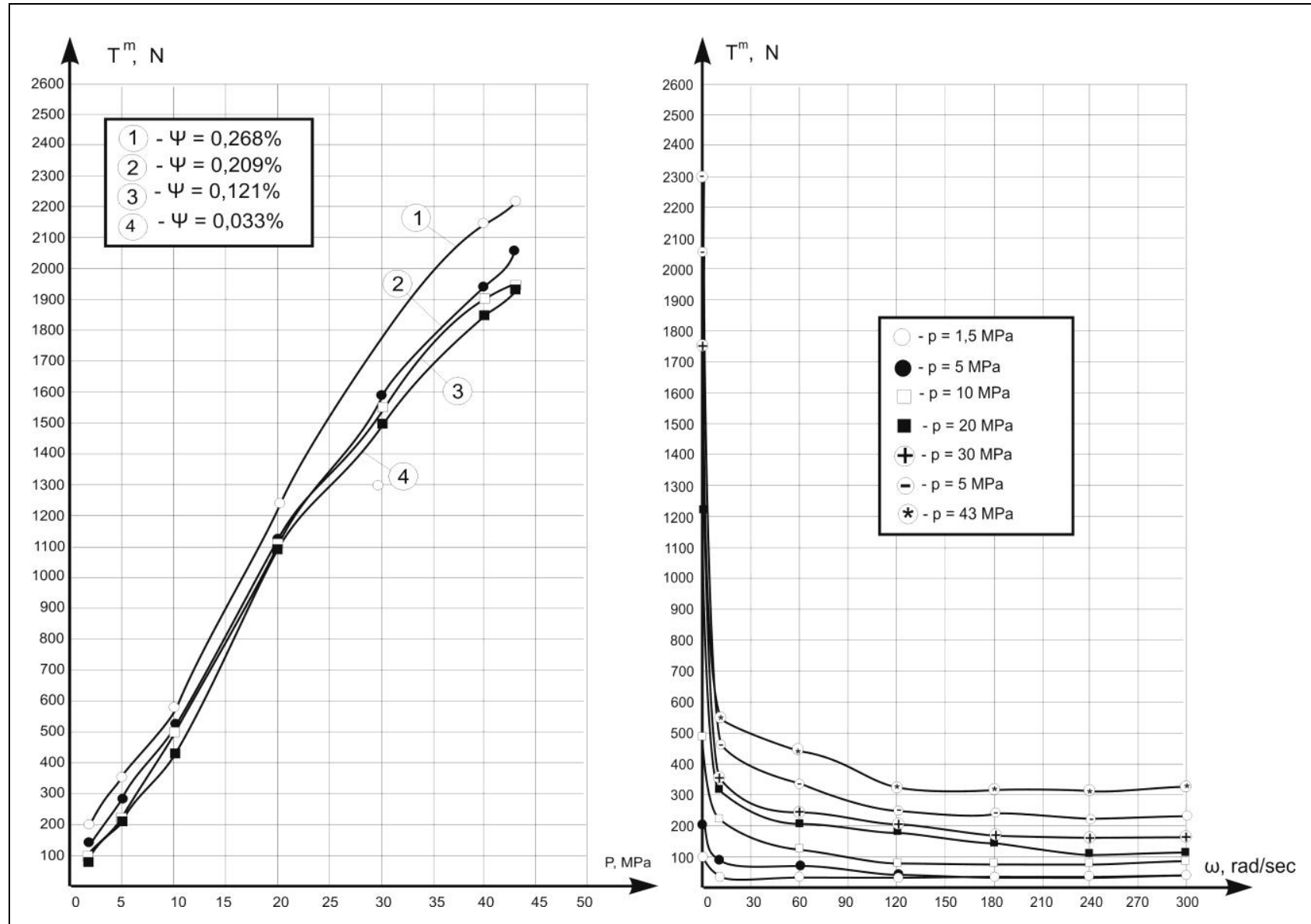

Fig. 11. Curves for axial component of friction forces in PCU with relative gap of $\Psi=0,033 \%$ versus driving shift angular frequency in motor mode

Fig. 12. Curves for axial component of friction forces in PCU versus hydraulic fluid pressure at creep speed (until 0,1 $\mathrm{rad} / \mathrm{sec}$ ) in motor mode

Researches showed that the shape and size of gap between meeting surfaces have a significant influence on listed characteristics. In the figures 13, 14 are shown the curves of friction forces in PCU versus the value of gaps for different operated pressure and rotation frequency of driving shift.

These relations allow to make a conclusion that the minimum friction force in $\mathrm{SWH}$ piston-cylinder unit can be reached with relative radial gap (relatively to the piston diameter) of $\varphi=0,12 \ldots 0,21 \%$.

Reduction of relative gap is facilitating the formation of bearing pressure. That is lead to earlier shifting from the boundary to liquid friction in CPU. Lower friction level PCU of hydraulic machine after its breakaway provides the tightness in "piston shoe - shoe plate" and "valve plate - cylinder block" kinematic pairs at lower rotation frequency of driving shift. That is important when high response and wide range of regulation, providing the low level of a minimum stable rotation frequency are necessary.

However, for a near ultimate speed and load for small-size gaps the simultaneously increase of friction forces and temperatures in kinematic pair are observed. Mentioned processes are occurred due to the lack of a heat removal of friction force energy in small-size gaps. Thereby, reduction the value of relative gap 
leads to limitation by the pressure of hydraulic fluid. That was confirmed with results of test in critical mode of hydraulic machine application.
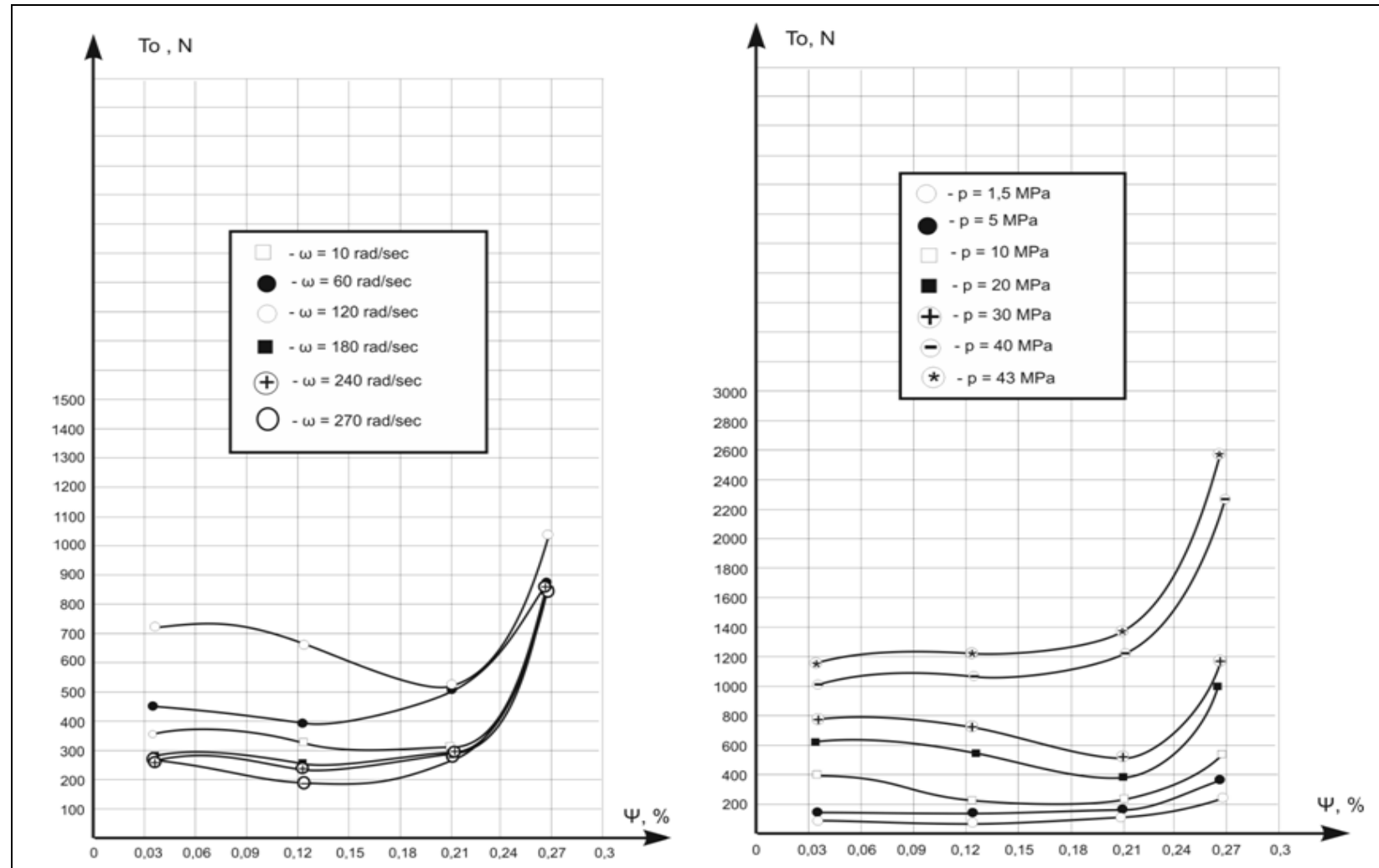

Fig. 13. Curves for sum of axial Fig. 14. Curves for sum of axial component of friction forces in PCU component of friction forces in PCU versus relative gap at pressure $\mathrm{P}=30 \mathrm{MPa}(\omega=10 \ldots 300 \mathrm{rad} / \mathrm{sec})$ versus relative gap at driving shift angular frequency $10 \mathrm{rad} / \mathrm{sec}$

On the base of structural, kinematic and power analysis were made recommendations for schematic and structural upgrading of SWH that applied as a hydraulic motor in power-consuming and high-accuracy drives.

From derived relation for friction coefficient in PCU for hydraulic machine operated in motor mode it follows that dislocation of spherical joint against the way of cross force acting significantly reduce the value of friction coefficient. Physical explanation is in partial or full making up of cross force torque exerted on the piston and axis force torque exerted on the arm of force that is equal to the spherical joint dislocation.

As a result of power analysis was derived relation for piston zero overturning torque. These are conditions by which the vector force, acting from the shoe plate on the piston mechanism, passes through the mounting surface of fairlead bush: $r_{c}=\left(L_{c a}-r_{n}\right) \cdot \operatorname{tg}(\gamma)$. From this relation it follows that for piston zero overturning torque (for researched SWH of $89 \mathrm{~cm}^{3} /$ revdisplacement) it is expediently to shift the spherical joint at $r_{c}=14 \mathrm{~mm}$ value. 


\section{Advanced Hydraulic Machine}

Take into account the fact that the orientation of spherical joint is fixed with cross force vector, exerted on the piston and direction of which during the piston work cycle is invariable. If there is a passive member, in given case the passive member is mounting shoe, the special arrangement that would provide the specified orientation of spherical joint is needful. That fact involve essential design problems or, as alternative, applying of the cylindrical joint. In this case the kinematic of piston mechanism become determined, that is because of the degree of motion changes and for advanced mechanism it sets equal to $W=1$. At that, the piston rotates in fairlead bush with equal to cylinder block frequency. Concerning the invariable orientation of mounting piston surface relatively to the cross force, for this case it is possible and expediently to make a hydrostatic unloading of piston-cylinder unit. The realization of hydrostatic unloading is presented in figure 15, it was made with using the circular angular flutes $(10,11)$.

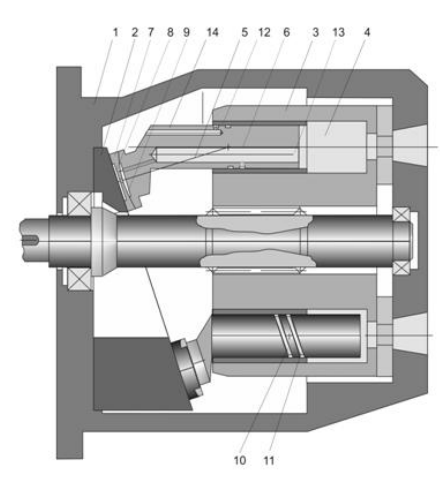

Fig. 15. Advanced swashplate axial-piston hydraulic machine

As was mentioned above, the condition for such design operation is that the piston rotates in fairlead bush cylinder block with equal to driving shift frequency. This term is realized when the torque for cross component of contact reaction between shoe plate and mounting surface of swash plate is higher then the sum of friction forces in kinematic pairs. The power analysis (see Fig. 16) of running gear mechanism allow to derive mathematical relation for junction nondisclosure between the mounting of piston mechanism and swash plate surface, in other words, condition of nonoverturning the mounting part of piston mechanism:

$$
\operatorname{tg}(\gamma)>f\left(\left(\frac{R_{p}}{\Psi_{p} \cdot F_{p}}\right) \cdot\left(\frac{r_{p}}{r_{m s}}\right)-\cos \left(\frac{r_{s}}{r_{m s}}\right)+\sin (\alpha) \cdot \cos (\gamma)\right),
$$

where:

$\gamma$ - tilt angle of swash plate,

$f$ - friction coefficient in piston cylinder unit, 


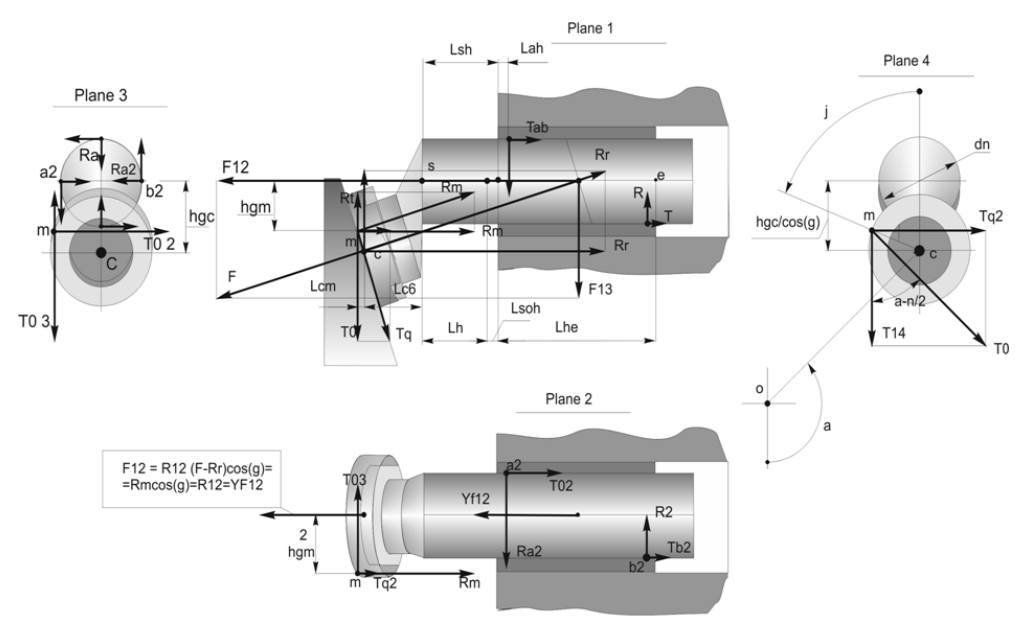

Fig. 16. The forces profile, exerted on the advanced piston mechanism

$R_{p}$ - sum of reaction in piston cylinder unit,

$\gamma$ - tilt angle of swash plate,

$f$ - friction coefficient in piston cylinder unit,

$R_{p}$ - sum of reaction in piston cylinder unit

$\Psi_{p}$ - coefficient of piston shoe and swash plate surface clamping force

$F_{p}$ - axial force, exerted on the piston

$r_{p}, r_{m s}, r_{s}$-the piston radius, the mounting surface of piston shoe radius, value of shift between the center of spherical joint and piston axial axis

$\alpha$ - angular coordinate of current position for piston mechanism

Computation of piston mechanism with following design factors:

$$
r_{m s}=14 \cdot 10^{-3} \mathrm{~m}, r_{p}=10,3 \cdot 10^{-3} \mathrm{~m}, r_{s}=13,3 \cdot 10^{-3} \mathrm{~m}, \Psi_{p}=0,034
$$

showed that junction disclosure at friction coefficient (coefficient of static friction in "steel - brass" pair) would occur when the tilt angle of mounting plate $\gamma<14,4^{\circ}$. At that, the shoe overturning takes place in motor mode phase (when the piston is extended) at $\alpha>135^{\circ}$.

Reasoning from this consequences and constructive demands to simplification and minimizing of changes of basic design were engineered and produced an advanced piston mechanisms for hydraulic machines with different swash plate angles.

Tests of the samples (see Fig. 17) were conducted by the two-piston experimental plant (see Fig. 8) with the basic piston mechanism research program. 


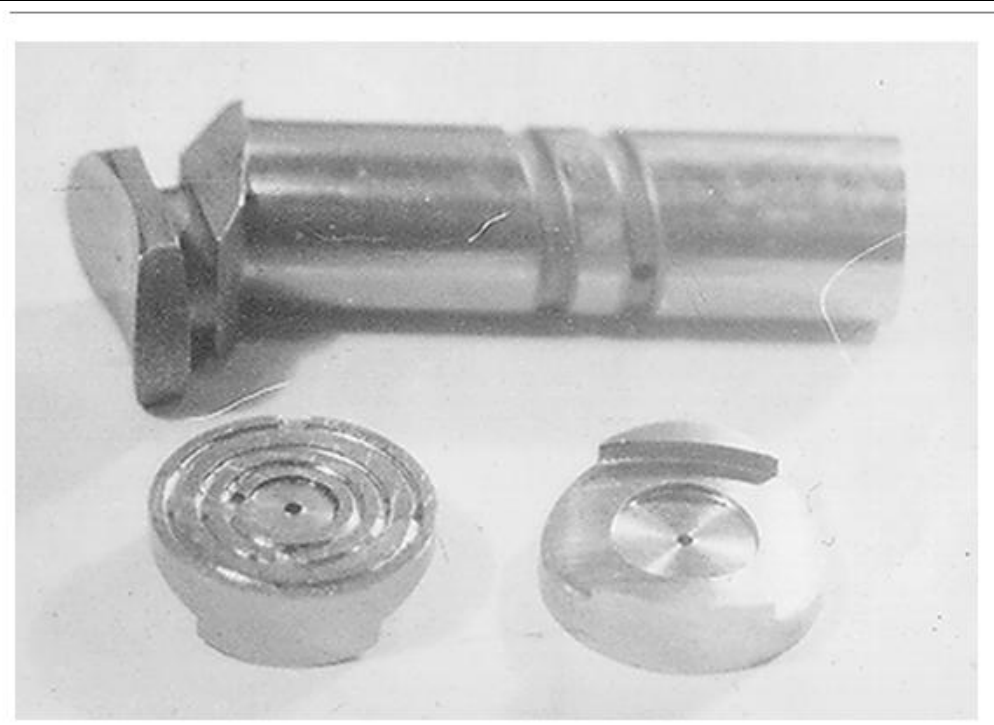

Fig. 17. Sample of advanced piston mechanism

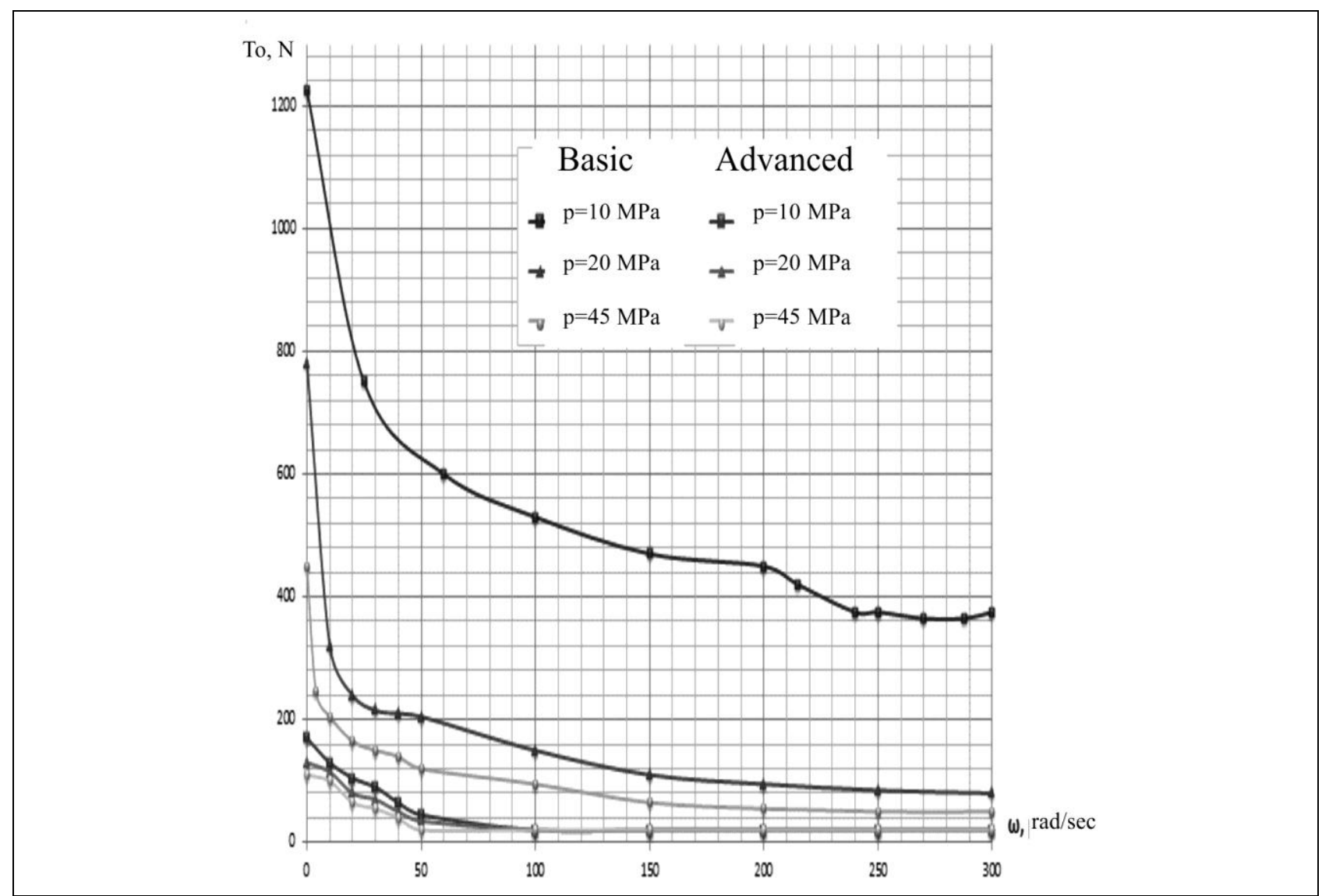

Fig. 18. Curves for axial component of friction force in PCU of basic and advanced hydromotors with relative gap $0,121 \%$ versus rotation frequency of driving shift

During the testing was verifying the relation for junction nondisclosure in kinematic pair "piston shoe - mounting plate". As a result of testing was determined that the most optimal for minimizing of power loss and considering the design demands was the advanced piston mechanism with swash plate angle $\gamma=18^{\circ}$.

On the base of the automated procession of friction force diagrams in PCU of advanced mechanism were derived relation between the axial component of friction 
force and rotation frequency of driving shift. In figure 18 there are comparison of relations for basic and advanced SWH.

As could be seen from given diagram, the friction forces in PCU of advanced hydromotors are of the next lower order comparatively with basic one. That allow with reasonable assurance to forecast the essential reduction of inert zone by reduction of minimum stable rotation frequency of driving shift. It should be noted that at high value of pressure and rotation the advanced piston mechanism have relative low level of mechanic loss. That is gives the reason for pressure and maximum rotation forcing of observed hydraulic machine type.

Tilted characteristics along with the engineering continuity of designed hydraulic motor concerning the traditional SWH scheme, allow to solve the current problem of increasing the power-consuming, coefficient of performance and dynamic characteristics of high power automated hydraulic rotary drive without large productive costs.

Scientific and practical results of given work allow to take a complex solution of theoretical and experimental researches of hydromechanical processes in SWH kinematic pairs concerning the changeable kinematic of running gears; also allow to determine practical recommendations of hydraulic machines members advancing. That is turn on a new opportunities for axial-piston hydraulic machines designing for power-consuming and high accuracy positive displacement hydraulic machines.

\section{References}

Artemyev T.V., Lysenko T.M. (2008). Hydraulics, hydraulic machines and externally controlled. M. Ed. "Academy", ISBN: 978-5-7695-5127-7

Holla IU. (2009). Design Hydrostatic transmissions, M. Ed. "Engineering", ISBN: 978-5-94275-427-3

Larchikov,I.A., Stazhkov,S., Yurov,A., The study of hydromecanical processes in hydromachines of power-intensive drives (2012. ) Annals of DAAAM for 2012and Proceedings of the 23th International DAAAM Symposium "Intelligent Manufacturing and Automation", Zadar, Croatia, 24-25th October 2012, ISBN 17269679,671-674

Lepeshkin A.V., Mihailin A.A., Belenkov Y.A. (2004). Hydraulic and pneumatic systems. M. Ed. "Academy", ISBN: 978-5-7695-5127-7

Regenbogen H. (1978) Das Reibungsverhalten von Kolben und Zylinder in hydrostatischen Axialkolbenmaschinen, (The friction behavior of pistons and cylinders in hydrostatic axial piston), VDI, Forschungsheft

Renius K.Th. Reibung zwischen Kolben und Zylinder bei Schagscheiben Axialkolbenmaschinen, (Friction between piston and cylinder at Schagscheiben axial piston) 